\title{
Process Of Reform. A View From The Teaching Personnel Of De University Of Nayarit.
}

\author{
Maria del Refugio Navarro Hernandez, Dra. \\ Lourdes C. Pacheco Ladron de Guevara, Dra. \\ Prisca Icela Romo Gonzalez, Dra. \\ Carmen Hernandez Cueto, Mtra
}

Universidad Autónoma de Nayarit

doi: 10.19044/esj.2016.v12n13p417 URL:http://dx.doi.org/10.19044/esj.2016.v12n13p417

\begin{abstract}
The university, as an institution, takes a long time to change, since its change does not happen as it does with organisms that transform completely. Rather, what characterizes universities is their resistance to change, their adaptation, counterproposals and negotiations (Porter 2003, Ibarra 2005, 2006), which are expressed with unique characteristics in each particular case. The apparent contradictions, in a complex and hard to unravel context, are that motivate this study. We ask whether such changes will create a new university or will lead it into an undesirable road; whether the university is able to defend its original goals. Can it experience transformation with the same strength and creativity today as with that was found in the collective conscience forty years ago? Can it maintain its spirit of commitment with its social, cultural, and ecological environment? Can it conserve its "sense of self”?

In order to understand how the essence of the university ethos is maintained or altered, "A university with sense of self" shows the ideas, attitudes, experiences and interpretations of the main actors at the Universidad Autónoma de Nayarit, the professors how they face these changes, and the "institutional reform" being proposed. We seek to explain how anticipated and desired change by the broader community in Nayarit, is in fact understood, assumed, lived, and carried out.
\end{abstract}

Keywords: University reform, change, humanistic teacher training, comprehensive

\section{Introduction}

This work is about how a Public Mexican University, (PMU), has faced external pressures to promote changes in both its organizational and 
academic model, often labeled under the title of "university reform". Confronted to this situation and depending on the subsidy to which these changes are tied to, the PMU has been forced to try to meet the requirements of national policies, from which depend its survival, and, on the other hand, it faces the obligation of preserving their fundamental values expressed in their mission statements that are part of the original project of the Public Mexican University, being this what is at stake today. This study was limited to a single PMU, which is in the state of Nayarit, since it is considered that the conditions are appropriate to be used as a case study that demonstrates that readers of other Mexican PUs may use them, as a reference, make comparisons and find similarities and differences.

\section{Research Purpose}

The present research was carried out to understand how the Autonomous University of Nayarit has faced the global and international pressures, which have been translated into very concrete policies in the national environment.

In this work we will study if these policies are accepted without any assessment or if they are adopted to produce necessary changes and in doing that to find out if the fundamental values of education are maintained, recovered or if they are definitely lost. These values are recorded in the original Project of the Institution and those are which maintain its social, regional character, they give life meaning and sense to its original vision and mission. This model of University is referred as the "traditional academic model”, and this preserves the immanent values which are characterizing thePUM. While the other model, that is induced by current policies (rooted since the eighties), is designated such the "university business model". It is not a matter of two opposite poles which in "black and white", allow us to observe what is really happening, but a way to approach to the atmosphere and to the processes of decisions which are the responsible ones of generating the changes that the University is passing through and they fluctuate between the two tendencies. It is important to highlight and recognize that we are looking, in this work, this long range of gray tones located between black and white in each one of the poles, which in turn becomes a qualitative work, subject to interpretations characteristics of hermeneutics itself, although we might not do specific reference to it.

We find that Public Universities not only in Mexico but throughout Latin America, are immersed in a constant crisis, not only in aspects of management, funding, evaluation and curriculum, but in its very conception as institutions with their own sense, so it is clear that all efforts made from within, by the witnesses of these processes, (such as the author of the present 
paper), perform analytical work to serve as testimony to what happens in the current dispute between two models or types of PMUs.

\section{Research Questions,}

By looking within the UAN, the tensions created by the policies to implement the "business model" on the one hand, and the defense and prevalence of the basic features of the "academic model", defended by scholars engaged on the other hand:

1) What are the evidences that allow us to stablish the effects of the proposed changes by the first model, against signs of permanence and evolution maintained by the second one?

2) What tendencies can be identified among members of the community of the UAN, in terms of actions of resistance in order to preserve certain values and actions to adapt themselves to the new rules of the game? And, in the case that both behaviors occur interspersed, what are the traits that assume the combination of the two of them?

3) If we agree that teachers are the main actors in these processes (although not the only ones), do they act with the awareness of this dispute between models?, or it is perceived simply as it occurs?, implementing spontaneous strategies of survival under the changing rules of the game?

\section{The reform of the university}

The UAN begins its reform process in the historical moment of transformation of the traditional University. This transformation is caused by two types of factors: one, arising from internal processes and the other one, from external processes to the University. The first one, professors' desire transform the university by entering into the trend of change, of innovation. The second one, federal policies require many things that result, in turn, from the global economy, information and technology. In these two frames the main challenge for universities is to preserve its 'raison d'être' in the future. (Lanz, 2003; Fergusson, 2003, Morin 2002)

At the time the process of reform at the UAN started we found that:

a) Evaluation was constituted as the regulatory mechanism of the fundamental work of teachers and researchers of the Mexican Public Universities. As a consequence, teachers were and had been stripped of the leadership and control of their work, and became subordinated to a complex bureaucratic machinery of collegiate offices, consisting of commissions of colleagues and administrative offices. The problem is that evaluation that is practiced does not intend any more to really be used as a means of evaluation; on the contrary, its fundamental purpose is in the management, as much as it might be possible, the behavior of professors, stripping them of the control of their work and products (Ibarra, 2002). By means of 
bureaucratic processes of certification, they become tied to academic structures that tell you what to do, how, when and in exchange of what.

b) Production of knowledge is not ruled anymore by the thought and a more reflective capacity, but by the production of useful knowledge, in terms of its conditions of application and their value in the market, or by the rampant publication of texts of dubious quality that almost nobody reads. It is a matter of creating a "new scholar" for a "new university", it is a matter of recreating identifies of individuals that nowadays are subject to the exigencies and conditions of the market, according to their knowledge and specialties.

c) The demand for greater educational quality has resulted in an increasing bureaucratic control that is responsible for verifying that teachers meet certain standards formally specified, little affecting the improvement of the educational process

d) The researcher is being reoriented through the paths of productivity, the piecework and the market, being subject to mechanisms of evaluation that operate after the certification of its products, taking into account levels of productivity and goals set by the federal authorities.

g) The transformation experienced by public universities is now one more of the transformations that have undergone universities through history. Each transformation has been linked to the events of the time, to the form they faced up and to the scientific and technical knowledge from which they are derived of.

h) Globalization or 'mondialisasion' (Derrida, 1989), as the French call it, has transformed the political, economic and financial systems, initiating a new world order, to the extent of upsetting the foundations on which society functioned in the previous centuries. It is even stated that a new civilization is setting off (Dias, 2000).

In this scene emerges the process of reform of the UAN, a process restricted by the pressure of public policy and economic changes, which in turn, are compelled by the multilateral organizations to strengthen the demand of a certain type of university. Exigencies of accreditation such as, efficiency, effectiveness, quality and pertinence are prioritized as indicators of competitiveness of achievement the universities in the world must strive for. For countries like Mexico, and in particular for the UAN, to meet these parameters, the university loses its meaning unless it is linked to the culture, idiosyncrasy, and world viewing of the peoples: in short, to the social and cultural context in which the university operates.

The challenge for the UAN is not easy: it is required of her to offer an education of higher quality, relevant, pertinent, competitive and strongly connected to the needs of society. These preceding caused a strong pressure at the time that the reform was decided. At one point the demands of the 
market were assessed and it was weighed the risk of making a technical university in training graduates without social commitment; at the same time it was also cautioned against the isolation of the university of the global changes and to train uncompetitive and obsolete graduate students. In short, how to propitiate a reform that retakes the humanistic education and setting off from this basis could be assessed its competitiveness?

As we all know, knowledge does not arise in vacuum, it is rather a historical product that responds to societal issues. It arises in a given society and responds to an epistemology, to a system of values, to a certain world vision and to specific interests. In this sense, the preponderance of sciencetechnology in the academic system is, at present, the result of the dominant model of western rationality. Both the cognitive processes, as well as the form of perceiving the world, the selection of problems, the approach of knowledge processes, to name a few, are the result of the predominance of a particular subject: the white male upper-middle class Western societies, (Fergusson, 2003), which spread their interests under the euphemism of containing universal interests. This way of conceiving the world has been consolidated through the time, enslaving the world views, the knowledge, the doings, the ways to learn languages and our cultures. This way of conceiving the world is what is accepted and enforced by that hegemony. In this sense, paradoxically, the demands to the University at the beginning of this new century and of which the UAN cannot be excluded from are:

i) To respond to a large contingent of excluded groups, when their integration into the university depends basically on entrance exams, and this leaves thousands of students without access to higher education.

ii) It is demanded to the University to promote diversity of education, but the other cultural ones are precisely those that do not have access to university education.

iii) The University must be prompted to remove the dangers of disappearing certain indigenous cultural systems, while at the same time; there is a demand for productivity, competitiveness, scientific and technical development, which prevents the development of the human sciences that would develop these cultural systems.

iv) The University must be responsible of addressing and stopping the serious consequences of environmental degradation in many parts of the country, while it is the faceless capitalism, the main predator, before universities can do little.

Today the whole world is undergoing a change of paradigm, undergoing a transition characterized by the placement of human capital at the center of the forces that determine the generation of wealth and contribute to achieve the ideals of social and development goals. The 
learning and knowledge have become a social demand for the development and welfare of societies, thereby generating an increasing demand for education, and especially, higher education. This requires cooperation among the disciplines, among the different centers of production of knowledge and culture, as well as of different knowledge (scientific, technical and artistic). In this context, education has been removed of what is at the core and center of the educational process to be only replaced by learning and by learning to learn.

In this scenario the UAN must not forget that it was and continues to be a key factor in the social change, since it is the only institution that promotes social development by bringing higher education to the various socio-economic strata that form it, because from its inception has joined to educate women, children of fishermen, farmers and workers, contributing, in this form, to social mobility, and somehow, particularly, in Nayarit, it has played a fundamental part in the development of democracy and peace.

Facing this situation, how the UAN must react to these processes of change? There is no doubt, in any circumstance, the university must:

i) preserve its soul, that is, to preserve the principle of universities

ii) be a place of autonomous reflection of research and dissemination of knowledge,

iii) be the center where any form of knowledge, of all sciences, of all cultures meet,

\section{The process of reform in the Autonomous University of Nayarit}

The reform of the university in the UAN is happening that was both desired and necessary, because the school operated with a traditional, outdated, vertical decision-making model that caused a poor response to the needs of students' training. It was necessary to make a new flexible curricula, offer new careers, try other forms of teaching, in short, a change was needed to revive and transform the inertia with which the university had worked for thirty years.

This reform, however, was proposed from the top dome of the university administration. Initially, there was a participation of the first levels of the administration, "stewardships, secretaries and coordinators of areas and the staff of the rector's office. Subsequently, second levels of management were involved in the decision-making,--program coordinators - and, once the process was approved, they began lobbying it with the other university actors. In the implementation of the reform there were not identified actors who opposed the reform, which is significant, because they followed the political and administrative processes that generally occurred within the practice of the uses and customs. 
However, legitimization occurs when it is promoted some kind of participation and some actors see it as an opportunity to change. In this form, the academic community participated by making proposals for the University transformation. Entrepreneurs, politicians, and NGOs also participated in it. They celebrated table discussions, forums and symposia which were organized by the rector's administration in order to achieve goals mentioned. The resulting proposals outlined the university that was expected to be by the different social actors.

Once this process was finished it was proceeded to work with the third levels: administrative personnel, professors, and sometimes with students. During that time were implemented strategies of change for the curriculum process itself, it was decided to opt for the teaching model through competencies, as the new curriculum model, (another mandate nationally ordered to be followed by the IES -Institutes of High Education).These strategies are more concerned with the forms than with the contents, and one of the most visible changes observed is the abandonment of the nomenclature of School / College to make way to the designation of Academic Units. The same happened with the nomenclature of subjects, or disciplines which were converted into Units of Learning. However, the changes were incorporated from the administration and first level top rulers, so that the teaching body which was supposed to be the main executing agents of change, lacked the necessary training for the use of the new classification and, consequently the contents of the system. Sometimes, the same committee responsible for curriculum changes was unaware of their practical application, as it was evident in the interviews that were made.

The incorporated changes that confronted teachers face to the adaptation of a new vocabulary marked by competencies, learning to learn, flexibility, education for democracy, learning new forms of assessment , vocabulary for which they were unprepared and it was unfamiliar for them. These unfamiliar vocabulary gradually becomes the official discourse. ending up as part of the everyday vocabulary. As it is concluded from the interviews, the changes of nomenclature and its implications were new to those teachers who were on the second level of decision making; they had doubts in the implementation of the processes.

Although there was some clarity in the theoretical description of the objectives that were intended to cover with the reform, practically, the professors did not know how to start the process to comply with these objectives. Given the fact that there was confusion at this level of the implementation of the reform, the doubts were magnified especially for most of the teachers who had not been invited to take part in the initial discussions. 
In this context, teachers saw themselves obligated to design their learning units through competencies, a model that was unknown to them. When deciding the contents, some teachers opted for their organization in academies, bodies of teachers around which the academic affairs has been organized. The proposed organization by academies was a response of the teachers themselves to build a group that allowed them to seize the contents of the reform. The organization by academies little by little has been consolidating itself with the purpose of carrying out the designing of the new characteristics of the learning units, their contents, the necessary practices, seminars, the development of teaching guides, the forms of evaluation, different ways of conducting the class, in short, everything that goes with the teaching-learning system under the context of what they consider the new model of learning through competencies.

These were the beginnings of changes in the curriculum. During the first year of the reform there were undertaken some efforts to train teachers in common areas. However, the teachers who were teaching disciplinary subjects received little training, so we may conclude that there was not a transition that would allow the trained teachers to understand and assimilate the changes. At a distance of five years since the reform started it is still confusion about the meaning of education through competencies and how to assess and conduct the process. Therefore, it still continues the traditional lecture-teaching and the traditional assessment.

The university reform has been unable to transform the academic teaching. Is it, by any chance, the task of the reform of the university, to bring about changes in a way that they change nothing? The same way the academic work remains unchanged, it also remain other areas of the University unchanged: the type of knowledge to be taught, the amounts of power, the authoritarian behavior (Tellez, 2006), can you really call a reform to this process that leaves the above mentioned unchanged?

The efforts that were made to induce the reform left out the aspects of the human training and the education for democracy, because it was focused on the technical aspects and on the explicit knowledge, leaving out the development of the tacit knowledge. All this is concluded from what was mentioned by the teachers in the interviews.

But how to teach for democracy, when the teacher does not live democracy? When he does not participate in democratic processes, democracy cannot be applied either. This is the case at the university where decision making is vertical.

How do teachers teach for citizenship? The teacher dedicates himself to transmit explicit knowledge, because it is the only thing that he knows and that he has done so far; he cannot claim to have participated in movements of citizens in which he had exercised a true and real citizenship. 
How to form in the assimilation of values? The teachers communicate the values of the traditional society which they are part of, a model of life marked by traditional values. Hence, the reform rises a formation of values without making clear which values must be assimilated.

How do they learn to live in freedom? The theme of freedom is controversial when it deals with the unraveling of the very meaning of freedom. At the level of university studies it is intended that the students are able to thinking with freedom, to build their own thinking assessment about the context they are living in. This becomes a utopia in an environment where teachers do not exercise freedom of thought. Utopia also becomes when the university itself is constrained to comply with rules and procedures which are determined and ordered by instances outside their area.

This way, the university's professor is driving himself, above his own formation, into the world of bureaucracy, forced by the rules under which he operates; although he realizes that sometimes he is making decisions that go against the university, against the university communities and the knowledge, and what is even more pathetic is that these decisions are presented as unreasonable actions that defy the most elementary common sense.

The purpose of education is now constrained to the demand of maximizing production, even by using grotesque patterns for measuring academic work by the number of graduates, tutorial appointments and publications, and, in short, for everything that can be scored into points. Under this logic, the only thing that matters is what can be counted; the rest simply does not exist.

The characteristics assumed by the implementation of the reform in the University of Nayarit are as follows:

i)

The reform had not a single pattern of implementation, neither a defined path, nor the same actors were involved in the process. The external consultants were changed and consequently changed the approaches on the reform. Furthermore, there was a change of administration at the rector's office.

ii) The axis of the reform was the change, but there was not a clear idea of what kind of University must be built. The reform resulted in changes of names but not in changes of academic processes

iii) Given the fact that the reform was desired by the university actors, the origin of the reform came from outside, because they attended the guidelines of an educational policy, which stemmed from recommendations made by international organizations. It lacked an internal movement to take the 
leadership of the reform as its own reform.

iv) The reform intends to respond to the social demands, but it does not built a real commitment

v) The reform emerged in the administrative circle and it has remained within the same circle.

vi) The implementation of the reform was heterogeneous because the different areas of knowledge have had different rhythms and trajectories

All this leads to a recognition that a reform like the one that was held in the Autonomous University of Nayarit requires resources to be carried out, it needs human resources, ideological resources and tools based on a true and genuine search for change, since there must be implemented different processes in different environments in order to make possible to obtain other academic productivity. This requires investment in infrastructure, in processes involving the training of those implicated in implementing the reform, in development of research, hence, it follows that those universities that have sufficient financial resources to achieve their goals can do it only and as long as these goals are well implemented. In contrast, a university such the UAN, with few resources and imprecise goals, is hardly able to achieve the indicators for national or international standards. Hence the issue of accreditation of academic programs becomes a vicious circle as it depends on the investment of resources and in turn, non-accredited universities do not have access to these resources by the lack of accreditation. However, here can be a space to reflect about: who determines the accreditation indicators? Are really "accredited universities better than those who are not? What evidence do we have of this? Have they done studies on the quality, relevance and impact of education in society? Are really those graduates from accredited programs best professionals who quickly find work and have an impact on the problem of the social environment? These questions mentioned above are remained for future studies.

The reality is that a government committed in college education tends to expand the coverage of higher education, to strengthen existing bodies and possibly to focus this issue on their objectives of social policies; to strengthen its democratic culture and a long term mechanism to achieve a more balanced development (De la Fuente, 2000). This attitude is precisely what is needed to universities: the strong support of federal agencies, but with confidence and wisdom in their academic institutions.

The current times demand that we confront the possibility and the need to transform the university, to recreate a project of social existence, which can be stripped of the post-ethical individualism (Lipovetsky, 1998), which was disseminated by the universal spread of markets and management. The challenge is now to reinvent the university under unprecedented and in- 
imagined patterns, to feed dialogues and conversations that lead to the social construction of the role of the university today (Ibarra Colado, 2006). It is a matter of building a university with the ability to understand and question the world, to think it otherwise, to reconstruct it down from the utopias that subvert the power of what is existing and what is set now, of everything that is fighting for in order to preserve their privileges. This will enable the road to establish dialogues and debates, in order to go beyond what we may think as isolated individuals, to build jointly, through the mobilization of our reflective abilities, this university which, indeed, is expected to be like.

\section{This is what has resulted of the process of the reform:}

When the reform began to be dealt in the forums about the university that we wanted, about the university that was desired, it started playing with ideal university projects, it appeared to shine some excellent ideas, some dreams about what the university was expected to be. They began to build a "University with its own meaning" a university built with dreams of its university population; the process began, no one questioned the reform, on the contrary all voices began to be heard, all the actors began to imagine the change, to talk and discuss about. It was made a return to the genesis of the university, recalling the process of its construction, the participation of citizens who yearned for their university, and, in this sense, it was perceived the need of the change for the people's University, for the University of Nayarit. This was the motor of the reform; this was what really triggered the reform. But like a balloon this spirit was lost little by little, it began to deflate. The educational model was imposed by force of the institutional mandates, the vertical power, this participation that was gained had to be given away to make place for contingency plans, to measures of survival. A hole was filled while there were opened three ones (of academic teachers). It led to improvisation. At a given time, the facts are no longer explained, processes and the most common actions, such as -how to teach a content through competencies, how to assess, how to certify a process.

The reform lost ground; on top of that it was perceived an absence of the creative and critical component of the university work. Maybe the strong ones did not know how to defend themselves? The active voices that were motivating the change blew out. It was accepted that change must be slow. Was the responsibility of the change left out? Was it left to the authorities? Or "the authorities seized the change?

This leads to suggest that the reform had not to be decreed; and that any process of reform requires a platform where actors are able to process differences democratically, where conflicts and contradictions find constructive channels of resolution, where projects may embody the reality of university. 


\section{Methodology:}

The methodology used was the analysis micro-politics because this method study the internal dynamics of an organization in several measures conditioned and determined by external forces.

The subjects were men and women between 25 and 50 years old who has different education background there some of them who are bachelors on science and arts other have a master degree and a few ones are PhD. The instruments were a semi-structure interview and a questionnaire.

\section{The answers to the questions of this research.}

To the research question posed from the macro framework of the original model of the PMU and observing the tensions created within the UAN for the implementation of the "business model ", on the one hand, and the defense and prevalence of the basic features of the "academic model ", guarded by committed scholars, on the other hand, what are the evidences that allow us to distinguish the effects of the proposed changes by the first ones, against the signs of permanence and evolution maintained by the second ones?

It must be answered that after five years of the reform the Autonomous University of Nayarit has not been able to construct a suitable subject, ready to seize the reform and carry it out, up to its latter consequences. In the practice, all academic, administrative and normative actions are heavily politicized and with a central management, making it impossible to the few efforts that are made from the basis, to define, somehow independently, the organizational model of a university with its own meaning, no longer come to a happy ending, but at least to bring about some changes aimed at making a "real reform". Hence, the reform has an administrative profile of fulfillment (ISO-9000, certification of the programs) but not generating processes that can change the dynamics of the academic tasks.

It is clear that building a new university under the old paradigm is impossible, so the university must build an agenda able to elucidate all the components of a genuine reform and to work on it, but above all, to strive to carry it out.

According to the results generated by this research, we can say that there is a loss of the relation among principles, since the economic resources that the university perceives do not allow UAN to meet the educational needs of the people, and also that the university teachers have forgotten the origin and social meaning of the university, especially the meaning of democracy prevailing in the Mexican people.

In relation to the question: What trends can be identified among members of the community of the UAN, in terms of actions of resistance in 
order to preserve certain values, and actions to adapt to new rules? And in the case that both behaviors occur interspersed, what traits assume this?

Surprisingly, although initially, in the first forums were given the opportunity to express the idea of university to the various actors, once started the reform there was no room for the debate, for argumentation, for criticism, so it was not possible to incorporate the real views of university teachers in the reform. Although somehow they made efforts to train university teachers, these were not widespread, they were small and segmented.

Similarly, teachers who participated in the first and second phases and were given information on how to carry out the changes, they devoted themselves to try to "comply," with whatever was immediate - since there was no time for more-, without questioning, without arguments, or arguing, there were even incorporated researchers and those who possessed a degreeto the critical mass of university teachers. Moreover, teachers who had to design their learning units (who were the most) exercising the office of teaching, that are not researchers and that in most cases have no degree, they that were not given any training, if anything, a talk on how to design courses through competencies. These were led by apathy, by "doing things the way they go out".

Either side objected, they were overwhelmed, planned or not, because the rush, the urgency, immediacy beat over prudence and wisdom. Once more, again future had over passed us.

In this sense the university professor lives the reform with some skepticism, perplexed and bewildered, especially by the poor preparation they had in this process of reform, and because of the immensity of the task. It was forgotten a golden rule: that all educational reforms should lead a debate on the training of the teachers, "educational reforms must come from the sensible principle according to which education cannot be changed without changing the procedures by which teachers are formed”. Again the teacher was the great "forgotten" of the reform.

Hence, although the teacher is aware of the disputes between the macro approach of federal policies and his own ways of thinking about education (micro view), little or nothing has been done, they are no longer overwhelmed by the neo-liberal vision of the fittest, of making the teacher to feel that he is not apt, he is not qualified, that to a grand extend, he is largely to blame for the crisis in education, and the best thing you can do is to accept their proposals and do what they say, under advertisement of being punished, (no access to promotions, scholarships, and other compensations).

This drives us to the next question "do teachers act with awareness of this dispute among models, or simply they perceive it as it occurs, suggesting spontaneous strategies of survival under the rules of the changing game? 
In this sense the university professor generally stuck to the game, therefore, all the teachers began to design contents and learning strategies according to the new model, but to do it, they tried to acquire the appropriate information to perform, as best as possible, their new task; for that they sought to form academies, as this would allow them to better understand the new processes and perform their new tasks. The establishment of the academies allowed the teachers to interact with other teachers, and this, I think, has been the most beneficial that has come out of the reform, it has allowed teachers to meet to talk, to debate, to share their knowledge and through this sharing they manifest their resistance, their dissatisfaction, their frustrations; but still it dominates the sense of duty, the desire to do the best for the university, one way to rescue that unique sense that has the Autonomous University of Nayarit. The university teacher in dealing up with the new pedagogical approaches does it out of his own philosophy of life, from his free will, he takes up what he considers relevant and ignores what is not, and somehow, he is planting the seeds of change, but keeping the humanistic principles of the university.

Regarding the first objective proposed in the research, to explain how are expressed the tensions between the model derived from the policies that tend towards the entrepreneurial university and to the humanistic university model with a regional commitment, which we call "the academic model"; there were identified the principles governing the reform, ranging from a training which is: comprehensive, democratic, of critical citizens, in solidarity, with equitable access to quality parameters such as productivity, effectiveness and efficiency, avatars of the neoliberal economic paradigm, that when they are transferred into practice they impact not only into the university but into the entire social structure. Therefore, it is true that the traditional university has fulfilled its historic function, and therefore is exhausted, but must not lose sight that the university needs to regain its social function and therefore the principles of liberal, integral and democratic education. The formation for citizenship must not be left, by no means, in the hands of those educational institutions that respond to the logic of the market.

According to the second research objective, which leads to identify the response of the University to the policies of reform and the implementation of entrepreneurial sense and academic organization, we can say that even though the world has changed and we are facing a new civilization with the new features of the global village, the principles behind education remain in force and therefore we should strive to reassume and strengthen them and make with them and out of them a bastion of the democratic life in the new dimension of this civilization. While it is true that the economic resources that enable the university to comply fully with the 
principles for which it was created will remain scarce, it is necessary that in this situation and despite the various requirements we have to be creative so that our university can respond to the needs of education of the society of today.

Regarding the last objective that leads to identify whether the relevant humanistic principles of the university with a regional sense in the educational endeavor, we found out that we have lost our sense of 'humanitas'; however, it is highlighted a new feature that cannot be ignored and that is what leads us to the position we take at the end of this document: fall in the temptation of losing our energy and hope and to believe that there is no alternative, no reform possible, that these are the rules of the game to which we must necessarily submit. We have to combat the impression that there is nothing we can deal up with versus these forces, the perception that institutional plans must necessarily take the form of PIFIS (Porter, 2003) or that our daily work must necessarily conform to the demands of the assessment programs by points. This fatalistic determinism assumes that our imprisonment is mandatory, therefore it is governed by forces that we cannot oppose unless we dismantle the institutional structures, under which higher education has operated in recent decades. By assuming that there is no alternative, we will continue subject to the rules dictated by the market and the politics or by the State that preserves and promotes them. We would not be writing the present paper and many others, under this pessimistic and immobilizing view, it would be in vain and without any sense because our aspirations would be unrealistic and we would declare our impotence against them.

However, in this bleak and conformist scenario we prefer to join the voices of contemporary philosophers who have analyzed the problems of the modern world in all its dimensions to indicate that any fatalistic and terminal theory is abstract and is wrong. The change at the individual level must also be at the institutional level. Following this position we can say that the battle for the reform of the university is not a battle of a few academics, nor the battle of those that are situated at the dome of the administration, neither of all of us who are at the bottom appealing to the hearts and minds of those holding the power of making decisions. It is not the hope or the fight for a change of attitudes, behaviors and positions to achieve through negotiations promoted by our individual discontent. No words can change an institutional territory that is essentially political. As we tried to show in this document, the loss of freedom, dignity, location and ownership that we are suffering, is the political consequence of this "instrumental reasoning" applied by the triumvirate SHCP-SEP-SESIC to institutions, increasingly constraining the ability of the academics to choose and decide according to their substantive reasoning expressed in the education, knowledge and culture. It is not a 
matter of theoretical speculation, but about the conditions of everyday life, leading to serious reflection on the presence that we are losing as individuals and as groups, to the extent that the wage is not simply what is affected, but our identity as human beings

Therefore, we are trying to recuperate the sense that once had the UAN, which again, is part of the people of Nayarit, the community of the university must seize this historic moment and we have to rebuild, shoulder to shoulder, this university of the people and for the people, not in the populist sense, but in a sense of constructing little by little the Nayarian, the Mexican and the citizen of the world, as the slogan of the university says: we have to go "from what is ours to what is universal," rescuing the idiosyncrasy, the traditions, the ways of seeing the world and our joy, that is, reaffirming our own being, and in this our own being, to make out of Nayarit a society developed in harmony, that is, to be happy.

\section{References:}

De la Fuente, J.R. (2000). Mensaje en la ceremonia de investidura de Profesores e Investigadores Eméritos. 25 de Septiembre. Consultado en febrero de 2006, disponible en: http://www.dgi.unam.mx/rector/mensajes/2000/25sep00.htm.

Derrida, J (1989). “Las pupilas de la universidad. El principio de razón y la idea de universidad”, en Cómo no hablar y otros textos. Barcelona, Proyecto A. Ediciones.

Dias, M.A. (2000) Integración y Educación. En Una solución a la crisis lationoamericana actual. Universidad de Deusto.Bilbao.

Fergusson, A. (2003) El debate sobre la Reforma Universitaria: una síntesis. Consultado en diciembre de 2006. Disponible en: http://www.ielsalc.unesco.org.ve/programas/reformas.

Fergusson, A. (2003) Relevamiento de experiencias de reformas universitarias en Venezuela. Informe Final. Proyecto IESALC/UNESCO. Consultado. Diciembre de 2006. Disponible en: http://www.ielsalc.unesco.org.ve/programas/reformas/venezuela/informefina l.pdf.

Ibarra Colado E. (2002). La “nueva universidad” en México: Transformaciones recientes y perspectivas. Revista Mexicana de Investigación Educativa, enero-abril, vol 7, núm. 14 pag. 77).

Ibarra Colado, E. (2006). Educación superior, entre el mercado y la sociedad: apuntes para mejorar su función social. Revista de Educación Superior, abriljunio XXXV (2) No. 128. ANUIES. México.

Lanz, R. (2003). Qué quiere decir “reforma universitaria”?. Informe Final ORUS-IELSAL-CUPEL. Caracas. 
Lanz, R. Comp. (2003). La Universidad se Reforma I Ed. ORUS-IELSALCUPEL.

Lipovetsky, Guilles. (1998). El crepúsculo del deber. La ética indolora de los nuevos tiempos democráticos. Barcelona, España. Ed. Anagrama.

Morin, E. et al. (2002). Educar en la era planetaria. Valladolid. UNESCO. UVA.

Porter, Luis (2003). La Universidad de Papel. Editorial Centro de Investigaciones Interdisciplinarias en Ciencias y Humanidades (CEIICHUNAM). México, D.F.

Tellez, G.O. (2006). Democracia y reestructuración académica en la UPN. Revista de la Educación Superior. Vol. XXXV(4) No. 140, OctubreDiciembre. 